\title{
Acute and Chronic Effects of Pulsed Phenol Exposure to Moina macrocopa
}

\author{
Jingbo $\mathrm{Xu}^{1, \mathrm{a}}$, Nan Jing ${ }^{2, \mathrm{~b}}$ and Chao Gao ${ }^{3, \mathrm{c}}$ \\ ${ }^{1,3}$ School of Environment, Northeast Normal University, Changchun 130024, China \\ ${ }^{2}$ Department of Logistics Engineering, South China University of Technology, Guangzhou 510006, \\ China \\ axujb515@nenu.edu.cn, bjingnan@scut.edu.cn, c gaoc339@nenu.edu.cn
}

Keywords: Moina macrocopa; pulsed phenol exposure; the parent generation (F0); the first generation of offspring (F1); EC50; 21-day cumulative mortality

Abstract. The toxicity of phenol to aquatic biota has been studied extensively for a long time. However, most studies have used a constant concentration aqueous exposure of phenol to an invertebrate species. This research was designed to characterize the toxicity effects of pulsed phenol $\left(\mathrm{C}_{6} \mathrm{H}_{5} \mathrm{OH}\right)$ exposure to Moina macrocopa. The $M$ macrocopa was exposed to $2.51,3.98,6.31,10.0$ $\mathrm{mg} \mathrm{C}_{6} \mathrm{H}_{5} \mathrm{OH} \mathrm{l}^{-1}$ at $6 \mathrm{~h}$ phenol pulses in this experiment. Our study demonstrated that the increase of pulsed concentration in the exposure of the parent generation $\left(\mathrm{F}_{0}\right)$ led to the decrease of $\mathrm{EC}_{50}$ and an increase of 21-day mortality of the first generation of offspring $\left(\mathrm{F}_{1}\right)$. The cumulative reproduction (21-day $C R$ ) of $F_{1}$ was significantly higher than this of $F_{0}$ when they experienced the same pulse.

\section{Introduction}

Pollution incidents of the aquatic environment often occur as pulses, such as discharge of storm water, overflow from sewage treatment plants, spraying of pesticides, industrial discharges, and runoff/drainage from fields during rain events ${ }^{[1,2]}$. Some studies have shown that such pulse discharges may result in even more pronounced effects than continuous discharges, but in the literature, most information regarding the aquatic toxicity of organic compounds is still based on continuous exposures ${ }^{[1,3]}$. Today, however, we still know little about the short-term and long-term toxic effects on phenol compounds during pulse exposures. Meanwhile, the offspring of exposed organisms may be affected during times of pulse and their responses are important to conduct more complete ecological risk assessment. The aim of the present study therefore was to investigate short-term $(48 \mathrm{~h})$ and long-term $(21 \mathrm{~d})$ effects of pulse exposures with phenol $\left(\mathrm{C}_{6} \mathrm{H}_{5} \mathrm{OH}\right)$ on mobility and reproduction in a model $M$ macrocopa. We propose that results obtained in this way be applied in effect assessments for intermittent releases, especially in an ecological or field context.

\section{Materials and methods}

$M$ macrocopa, an important and cosmopolitan group of zooplankton in freshwater, were used in the present study. The cladoceran M. macrocopa clone (from the Chinese Academy of Sciences, Wuhan, PR China) used in this study had been cultured in our laboratory for more than 5 years. M. macrocopa were fed a suspension of the unicellular green alga Pseudokirchneriella subcapitata three times a day. The feeding rate was $2 \times 10^{5}$ cells $/ \mathrm{ml} / \mathrm{d}$. Algae were grown in the medium described in the International Organization for Standardization (IOS) guideline $8692^{[4]}$.

The $48 \mathrm{~h}$ acute toxicity tests using $M$. macrocopa were conducted according to the OECD standard operating procedure $202^{[5]}$. Based on acute toxicity tests, appropriate concentrations were selected for the pulse-exposure tests. Two-days-old $M$. macrocopa were used in the experiment. Pulse-exposure time was $6 \mathrm{~h}$. After exposure, organisms in each beaker were transferred to control culture media in clean beaker and maintained until the test termination (21-d). Offspring and dead organisms were removed daily. 
Water chemistry was characterized at the start and end of exposures and weekly during each test according to OECD standard methods. The $\mathrm{pH}$ and dissolved oxygen concentration, hardness, and alkalinity in all test waters were $7.39 \pm 0.06,8.24 \pm 0.03 \mathrm{mgl}^{-1}, 106 \pm 5 \mathrm{mg} / \mathrm{l}$ as $\mathrm{CaCO}_{3}$, and $65 \pm 3 \mathrm{mg} / \mathrm{l}$ as $\mathrm{CaCO}_{3}$, respectively.

To ensure agreement between nominal and actual phenol concentrations in the aquaria, water samples were analyzed during the experimental period by LC-MS/MS. Water samples were collected from the test aquaria after $1 \mathrm{~h}$ and $24 \mathrm{~h}$ of renewing the test solutions.

The statistical analysis was performed using a one-way ANOVA (Origin 8.0 Corporation, USA). The 48-h EC $_{50}$ and their 95 percent confidence limits were calculated. Student $t$ test was applied to study the relationship between the different concentration samples. A $p<0.05$ was considered to be significant.

\section{Results}

Acute toxicity tests : The $\mathrm{EC}_{50}$ values generated by phenol to the $\mathrm{F}_{1}$ generation are presented in Fig. 1. The parents were abbreviated to $F_{0}$. The first generation was abbreviated to $F_{1}$. On the scale of test, the $\mathrm{EC}_{50}$ of $\mathrm{F}_{1}$ declined continuously with the increase of pulsed concentrations of $\mathrm{F}_{0}$. As shown in Fig.1, all $\mathrm{EC}_{50}$ values were lower than control. Specially, the $\mathrm{EC}_{50}$ values of 6.31 and $10.0 \mathrm{mg}$ $\mathrm{C}_{6} \mathrm{H}_{5} \mathrm{OHI}^{-1}$ were significantly decreased compared with the control $(p<0.05)$
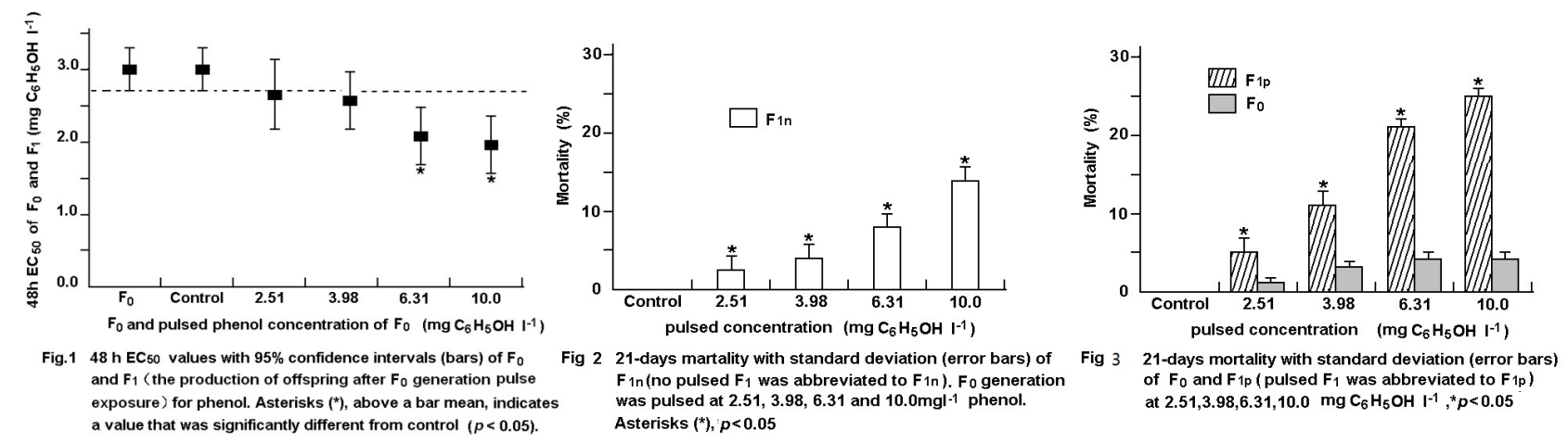

21-days mortality: In the present study 21-days mortality of no pulsed $F_{1}$ (no pulsed $F_{1}$ was abbreviated to $F_{1 n}$ in Fig. 2) was affected by pulsed phenol exposure of $F_{0}$ generation. 21-days mortality of $F_{1}$ increased continuously with the enhancement of pulsed concentrations of $F_{0}$ (Fig. 2). After a single pulse of phenol, the 21-day mortality of $\mathrm{F}_{0}$ generation was all less than five percent at 2.51, 3.98, 6.31 and $10.0 \mathrm{mgC}_{6} \mathrm{H}_{5} \mathrm{OHmgl}^{-1}$ exposure and differences between control and treatment groups were not obvious (Fig.3). But for pulsed $F_{1}$ generation (pulsed $F_{1}$ was abbreviated to $F_{1 p}$ in Fig. $2 \mathrm{~b}$ ), the 21-day mortality is 5 percent, 11 percent, 21 percent and 25 percent at the four phenol treatments, respectively.

Reproduction: Effects of pulsed phenol exposure on the reproduction of $M$. macrocopa are presented in Table 1. Pulsed phenol exposure on the reproduction consisted of four concentrations, ranging from 2.51 to $10.0 \mathrm{mg} \mathrm{l}^{-1}$. There is no significant difference between phenol treatments and control of $\mathrm{F}_{0}$ on time to first brood (TFB, age at which organism produce the first neonate generation) and 21-d CR (cumulative reproduction). Pulsed phenol exposure decreased 21-d CR of $F_{1 n}$ at the highest treatment concentration $10.0 \mathrm{mg} \mathrm{l}^{-1}(p<0.05)$. However, this reduction $21-\mathrm{d} \mathrm{CR}$ of $\mathrm{F}_{1 \mathrm{n}}$ did not resulted in a change on the corresponding TFB $(p>0.05)$. A significant effect on 21-d CR of $F_{1 p}$ occurred in $3.98 \mathrm{mgl}^{-1}$ and higher, but no significant inhibition on TFR occurred at concentration below $10.0 \mathrm{mg}^{-1}$. $(p>0.05)$. 
Table 1 Reproduction of $M$. macrocopa pulsed to phenol in the control group and exposed groups $\left(2.51,3.98,6.31\right.$ and $\left.10.0 \mathrm{mg} \mathrm{C}_{6} \mathrm{H}_{5} \mathrm{OH} \mathrm{l}^{-1}\right)$. All values are means $\pm \mathrm{SD}(\mathrm{n}=4)$. Asterisks $(*)$ represent $p$ $<0.05$ (Significantly different from control).

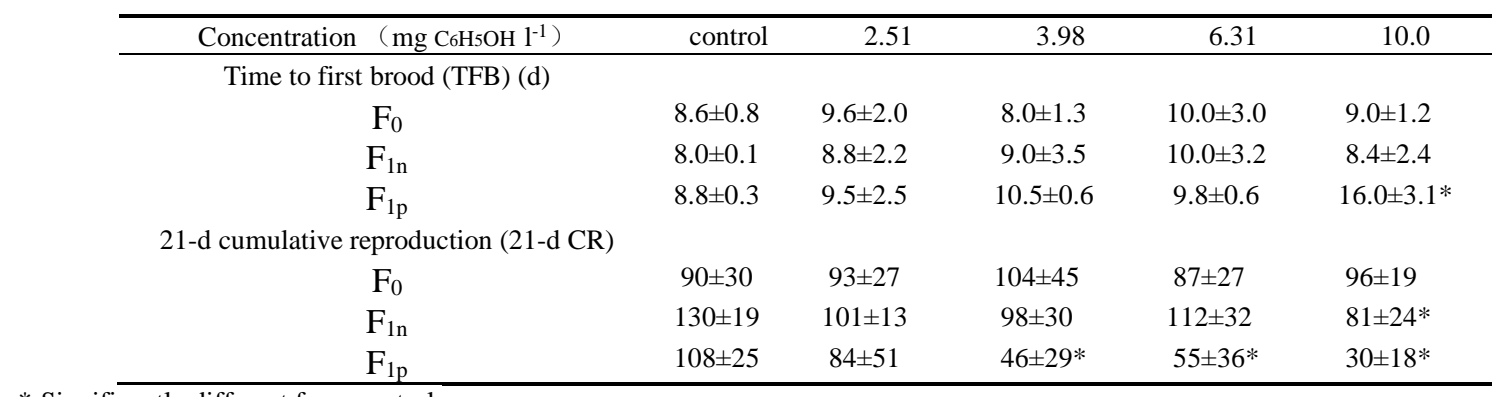

* Significantly different from control.

\section{Discussion}

$\mathrm{EC}_{50}$ and 21-Days mortality: Delayed effect which most often was represented by latent mortality of exposed organism themselves has been as a predictor of pulse exposure ${ }^{[6-8]}$. The response of offspring to pulse exposure, however, remains largely unknown. In the present study, the survival state of $\mathrm{F}_{0}$ was little affected after pulsed four concentrations, $6 \mathrm{~h}$ phenol exposure and latent mortality was less than five percent in 21 days of observation. But the $\mathrm{EC}_{50}$ of $\mathrm{F}_{1}$ dropped continuously as the pulsed copper and phenol exposure of $\mathrm{F}_{0}$ added. As shown in Fig. 1, the $\mathrm{EC}_{50}$ values was significantly lower with 6.31 and 10.0 phenol mgl ${ }^{-1}$ than in the control in our experiments $(p<0.05)$. The offspring of $M$. macrocopa which were exposed 6.31, $10.0 \mathrm{mgC}_{6} \mathrm{H}_{5} \mathrm{OH} \mathrm{l}^{-1}$ should distinctly reduce tolerance to phenol compared to control. Our data show that the reduction of $\mathrm{EC}_{50}$ to $\mathrm{F}_{1}$ is closely correlated with the pulsed phenol exposure of $F_{0}$. Perhaps for trans-generation effect the moment that pulsed exposure of $\mathrm{F}_{0}$ occurred might need to be considered more comprehensive.

Reproduction: There is no significant difference on TFB and 21-d CR between phenol treatments and control $M$. macrocopa of $\mathrm{F}_{0}$ generation in this study. Hoang et al. reported that growth and reproduction of surviving $D$. magna were not affected by single pulsed Se exposure ${ }^{[8]}$. The result is similar to our experiment data. Hosmer et al. found there were no significant effects on AFR of first and second generation $D$. magna in any age group ${ }^{[9]}$, but he did not investigate the effect on 21-CR. Our experiments show that there is no difference in the TFB of $F_{1 n}$ (no pulsed $F_{1}$ was abbreviated to $\mathrm{F}_{1 \mathrm{n}}$ ), compared to control, but the $21-\mathrm{CR}$ of the $\mathrm{C}_{6} \mathrm{H}_{5} \mathrm{OH} 10.0 \mathrm{mgl}^{-1}$ were lower than the control (Table $1 p<0.05)$. In absence of compensatory processes, stressful environmental conditions would be expected to negatively impact growth, energy storage and reproduction ${ }^{[10,11]}$.

The toxic effects of continuous phenol exposures have been documented. However, virtually no information on the toxicity of pulsed phenol exposures on $M$. macrocopa exists, despite such exposures being expected to occur frequently in the field from anthropogenic sources such as effluent discharges and pesticide applications ${ }^{[12]}$. There is also a lack of research on the chronic effects of pulsed copper exposures. So far, the limited data made by researchers are insufficient to answer the reproduction toxicity effects of pulsed phenol $\left(\mathrm{C}_{6} \mathrm{H}_{5} \mathrm{OH}\right)$ exposure to Moina macrocopa. A significant inhibition on 21-d CR of $\mathrm{F}_{1 \mathrm{p}}$ occurred at concentrations of $3.98 \mathrm{mg} \mathrm{C}_{6} \mathrm{H}_{5} \mathrm{OH} \mathrm{l} \mathrm{l}^{-1}$ and higher, but no significant inhibition on TFB occurred at concentration below $10.0 \mathrm{mg} \mathrm{C}_{6} \mathrm{H}_{5} \mathrm{OH}$ $1^{-1}$ (Table 1).

Intermittent, fluctuating and pulsed contaminant discharges result in organisms receiving highly variable contaminant exposures ${ }^{[12]}$. We propose that results obtained in this way be applied in effect assessments for intermittent releases, especially in an ecological or field context.

\section{Conclusions}

Our study demonstrated trans-generation effects of pulsed $\mathrm{C}_{6} \mathrm{H}_{5} \mathrm{OH}$ exposure on $M$. macrocopa. Based on the results, the mortality of first filial generation $\left(\mathrm{F}_{1}\right)$ was significantly higher level than 
parent generation $\left(\mathrm{F}_{0}\right)$ when they experienced the same phenol pulse. The increase of pulsed phenol concentration of parent generation $\left(\mathrm{F}_{0}\right)$ can lead to the decrease of $\mathrm{EC}_{50}$ and the increase of 21-day cumulative mortality in first filial generation $\left(\mathrm{F}_{1}\right)$. The decline in $\mathrm{EC}_{50}$ and the increase of 21-day cumulative mortality in first filial generation $\left(\mathrm{F}_{1}\right)$ can be caused by increased pulse concentration of phenol to parent generation $\left(\mathrm{F}_{0}\right)$.

\section{Acknowledgements}

This study was financially supported by the National Natural Science Foundation of China (No. 31570507).

\section{References}

[1] A.W. Brooks, L. Maltby, A.J. Saul and P. Calow: A simple indoor artificial stream system designed to study the effects of toxicant pulses on aquatic organisms. Water Research Vol.30 (1996), p.285-290.

[2] T.H. Andersen, R. Tjornhoj, L. Wollenberger, T. Slothuus and A. Baun: Acute and chronic effects of pulse exposure of Daphnia magna to dimethoate and pirimicarb. Environmental Txicology \& ChemistryVol.25 (2010), p.1187-1195.

[3] KA. Tucker, G.A. Burton:Assessment of nonpoint-source runoff in a stream using in situ and laboratory approaches. Environmental Toxicology \& Chemistry Vol.18 (2010), p.2797-2803.

[4] ISO.ISO8692Water quality-freshwater algal growth inhibition test with Scenedesmus subspicatus and Selenastrum capricornutum.Geneva: International Organization for Standarzation, 2012.

[5] OECD. Guideline for testing of chemicals No.202Daphnia sp. acute immobilization test and reproduction test.Paris: Organization for Economic Cooperation and Development, 2004.

[6] J.J. Rasmussen , P. Wiberg-Larsen, E.A. Kristensen, N. Cedergreen and N. Friberg. Pyrethroid effects on freshwater invertebrates: A meta-analysis of pulse exposures. Environmental Pollution Vol.182 (2013),p.:479-485.

[7] Y. Zhao, M.C. Newman: Shortcomings of the laboratory-derived median lethal concentration for predicting mortality in field populations: exposure duration and latent mortality. Environmental Toxicology \& Chemistry Vol. 23 (2010), p.2147-2153.

[8] T.C. Hoang , J.R. Tomasso and S.J. Klaine: An integrated model describing the toxic responses of Daphnia magna to pulsed exposures of three metals. Environmental Toxicology \& Chemistry Vol.26 (2010), p.132-138.

[9] A.J. Hosmer, L.W. Warren and T.J. Ward: Chronic toxicity of pulse-dosed fenoxycarb to Daphnia magna exposed to environmentally realistic concentrations. Environmental Toxicology \& Chemistry Vol.17 ( 2010), p.1860-1866.

[10] C.Zehnder: Metabolic costs incurred by crayfish (Procambarus acutus) in a trace element-polluted habitat: further evidence of similar responses among diverse taxonomic groups. Comparative Biochemistry \& Physiology Part C Toxicology \& Pharmacology Vol.129 (2001), p.275-283.

[11] J.Xu, N.Jing: Effects of 2,4-dinitrotoluene exposure on enzyme activity, energy reserves and condition factors in common carp (Cyprinus carpio). Journal of Hazardous Materials Vol. 203 (2012), p.299-307. 
[12] B.M. Angel, S.L. Simpson, A.A. Chariton, J.L. Stouber and D.F. Jolley. Time-averaged copper concentrations from continuous exposures predicts pulsed exposure toxicity to the marine diatom, Phaeodactylum tricornutum : Importance of uptake and elimination. Aquatic Toxicology Vol. 164(2015), p.1-9. 